\title{
Aprendizagem Baseada em Projetos no Ensino Médio: estudo comparativo entre métodos de ensino
}

\section{Project-Based Learning in Math Teaching: comparative study between teaching methods}

\author{
Sebastião Luís de Oliveira * \\ ORCID iD 0000-0002-2522-0558 \\ Adriano Francisco Siqueira ** \\ ORCID iD 0000-0002-6920-7507 \\ Estaner Claro Romão ${ }^{* * *}$ \\ ORCID iD 0000-0003-4316-2029
}

\begin{abstract}
Resumo
Novas metodologias de ensino estão sendo utilizadas em sala de aula como forma de propiciar uma melhor aprendizagem dos conteúdos curriculares. As modificações sociais, econômicas e tecnológicas do mundo contemporâneo, impõem ao sistema educacional, a necessidade de desenvolver novos modelos de ensino e aprendizagem. O presente trabalho teve como objetivo comparar estatisticamente, em duas turmas de alunos, o método de ensino expositivo e a aprendizagem baseada em projetos, concomitantemente ao ensino tradicional. Utilizamos um delineamento experimental tendo como variável independente o método de ensino, e como variáveis independentes, a motivação para aprender, atitudes em relação á Matemática e o desempenho escolar. Os resultados encontrados foram: nos aspectos motivação para aprender e atitudes em relação à Matemática não foram encontradas diferenças significativas entre os métodos de ensino. No aspecto desempenho escolar, uma das turmas no qual se utilizou a aprendizagem baseada em projetos teve melhor desempenho do que a turma que utilizou o método de ensino expositivo. Os resultados indicam que a aprendizagem baseada em projetos é um método de ensino exequível na Educação Básica com resultados ligeiramente superiores ao método de ensino expositivo tradicional.
\end{abstract}

Palavras-chave: Ensino de Matemática. Aprendizagem baseada em Projetos. Educação Básica.

\footnotetext{
* Mestre em Ciências pela Universidade de São Paulo. Professor Docente I da Secretaria de Estado de Educação do Rio de Janeiro, Rio de Janeiro, Brasil. Endereço para correspondência: Rua Aldrovando de Oliveira, 174 Bairro Ano Bom, Barra Mansa, Rio de Janeiro, Brasil, CEP 27323-350. E-mail: sebastiao.oliveira @ifrj.edu.br.

** Doutor em Estatística pela Universidade de São Paulo. Professor Doutor na Escola de Engenharia de Lorena da Universidade de São Paulo, Lorena, São Paulo, Brasil. Endereço para correspondência: Estrada Municipal do Campinho s/n, Área 1, Departamento de Ciências Básicas e Ambientais, Lorena, São Paulo, Brasil, CEP: 12606452. E-mail: adrianoeel@usp.br

*** Livre Docente em Cálculo I, II, III e IV pela Universidade de São Paulo. Professor Associado na Escola de Engenharia de Lorena da Universidade de São Paulo, Lorena, São Paulo, Brasil. Endereço para correspondência: Estrada Municipal do Campinho s/n, Área 1, Departamento de Ciências Básicas e Ambientais, Lorena, São Paulo, Brasil, CEP: 12606-452. E-mail: estaner23@usp.br
} 


\begin{abstract}
New teaching methodologies are being used in the classroom as a way to promote better learning of curricular contents. The social, economic, and technological changes of the contemporary world impose on the educational system the need to develop new models of teaching and learning. The objective of this study was to compare, in two classes of students, the method of expository teaching and project-based learning concomitantly with traditional teaching. We used a experimental design with the teaching method as an independent variable, and as independent variables, the motivation to learn, attitudes towards mathematics, and school performance. The results found were: in motivation to learn and attitudes in relation to mathematics no significant differences between the teaching methods were found. Regarding school performance, one of the classes that used projectbased learning had a better performance than the one which used the method of expository teaching. The results indicate that project-based learning is a feasible teaching method in basic education with results slightly higher than the traditional teaching method.
\end{abstract}

Keywords: Mathematics Teaching. Project-based Learning. Basic Education.

\title{
1 Introdução
}

Este trabalho buscou investigar os efeitos motivacionais e de aprendizado, na disciplina de Matemática, de duas turmas de Ensino Médio de uma escola pública do estado do Rio de Janeiro. O estudo consistiu em comparar estatisticamente diferenças entre o método tradicional expositivo e uma metodologia ativa de ensino denominada Aprendizagem Baseada em Projetos. Para tanto, utilizou-se um delineamento de pesquisa experimental com aplicação de instrumentos de pré-teste e pós-teste.

Métodos de ensino que promovam a maior aprendizagem, motivação e engajamento dos alunos no processo de aprendizagem são objetos de estudos atualmente. Pavanelo e Lima (2017, p. 740) citam que "estudiosos da área defendem há décadas um novo modelo de educação, em que o aluno seja o protagonista e aprenda de forma mais autônoma". Ou seja, o aluno saia de uma posição passiva em que é apenas um receptor de conteúdo para uma atitude ativa e participativa em sua própria aprendizagem.

Desse modo, o sistema educacional necessita se adequar a um novo paradigma que privilegie o desenvolvimento de capacidades cognitivas superiores tais como, por exemplo, análise, síntese e criatividade. Em substituição aos processos de simples memorização e repetição de algoritmos conforme argumentam (DIESEL; BALDEZ, MARTINS, 2017, p. 271), "Enquanto o método tradicional prioriza a transmissão de informações e tem sua centralidade na figura do docente, no método ativo, os estudantes ocupam o centro das ações educativas e o conhecimento é construído de forma colaborativa".

Neste sentido, destacamos os estudos com a utilização de uma metodologia ativa de ensino. Citamos como exemplos, os trabalhos de Vianna et. al. (2016) e Martins et. al. (2016) realizados em escolas técnicas de Ensino Médio, cujos resultados indicaram maior 
envolvimento e participação dos alunos nas atividades educacionais, eficiência e otimização do aprendizado.

Corroborando o citado, (MORAN, 2015, p. 17) afirma que,

As metodologias precisam acompanhar os objetivos pretendidos. Se queremos que os alunos sejam proativos, precisamos adotar metodologias em que os alunos se envolvam em atividades cada vez mais complexas, em que tenham que tomar decisões e avaliar os resultados, com apoio de materiais relevantes.

Agrega-se a este cenário a necessidade do sistema educacional adequar-se às novas demandas de uma sociedade altamente tecnológica e em processo constante de inovação, a qual a simples memorização de fatos e dados, características marcantes do ensino expositivo tradicional, não atende.

Para atender a esta nova sociedade, o aluno egresso da Educação Básica deve possuir habilidades e competências tais como: resolução de problemas, pensamento crítico, comunicação de ideias e cooperação.

Para isso, uma alternativa é o uso de metodologias ativas no ensino, que dentre as existentes selecionamos a Aprendizagem Baseada em Projetos (ABP) que possibilita, segundo Bender (2014), o desenvolvimento das habilidades e competências do século XXI,

\begin{abstract}
A ABP pode ser definida pela utilização de projetos autênticos e realistas, baseados em uma questão, tarefa ou problema altamente motivador e envolvente, para ensinar conteúdos acadêmicos aos alunos no contexto do trabalho cooperativo para a resolução de problemas. [...] A investigação dos alunos é profundamente integrada à aprendizagem baseada em projetos, e como eles têm, em geral, algum poder de escolha em relação ao projeto do seu grupo e aos métodos a serem usados para desenvolvê-los, eles tendem a ter uma motivação muito maior para trabalhar de forma diligente na solução de problemas (BENDER, 2014, p. 15).
\end{abstract}

Segundo Larmer, Mengendoller e Boss (2015), a ABP desenvolve habilidades essenciais aos desafios do século XXI, na qual se destacam a habilidade na resolução de problemas, sentido de responsabilidade, trabalho em pares, pensamento crítico, autoconfiança, gerenciamento de tempo, transmissão de ideias e pensamentos por meio da comunicação com outras pessoas. Logo, a ABP é um método de ensino que estimula a aprendizagem dos conteúdos programáticos por meio do envolvimento dos alunos em situações reais e desafiadoras. Desse modo, os alunos podem gerar suas próprias ideias e hipóteses, aplicandoas e aprendem fazendo.

Krajcik e Blumenfeld (2006) reportam que a ABP permite aos alunos aprender fazendo e aplicando suas ideias. Eles se envolvem em situações reais similares às que profissionais de uma determinada área de trabalho se envolvem. Acrescentam ainda que a ABP é baseada na teoria construtivista que relata um maior entendimento do assunto quando os alunos participam ativamente na construção e no uso de suas próprias ideias. 
Gardner (1995) argumenta que, quando os indivíduos estão empenhados em projetos significativos, relativamente complexos, atraentes e motivadores, são conduzidos ao desenvolvimento do entendimento e da habilidade. O mesmo autor destaca que a maior parte da vida produtiva de uma pessoa consiste do seu envolvimento em projetos, sejam eles pessoais, profissionais ou de uma comunidade.

No contexto da Educação Matemática, o trabalho com projetos é citado por D’Ambrósio (2010) e Maltempi (2009) que argumentam sobre a importância dos mesmos, uma vez que este tipo de metodologia é uma forma de trabalhar experimentalmente os conceitos matemáticos, à medida que a elaboração de um projeto envolve a construção de um artefato que é o resultado da materialização de ideias, similar ao que fazemos em nosso dia a dia. Enquanto isso Costa, Pinheiro e Pilatti (2012) consideram que projetos contribuem para a Educação Matemática no sentido em que desenvolvem a interdisciplinaridade, a resolução de problemas, o espírito investigativo dos alunos e permite o relacionamento entre os conteúdos escolares e a vida cotidiana.

Ratificando o citado, Cardoso e Santos $(2014$, p. 1) argumentam que "a aprendizagem matemática não consiste apenas em desenvolver capacidades como calcular ou fixar conceitos pela memorização". Em outras palavras, consiste em estabelecer estratégias que possibilitem ao aluno atribuir sentido e construir significado para as ideias matemáticas, participando ativamente do processo de aprendizagem.

Por outro lado, Cardoso e Santos $(2014$, p. 2) argumentam que "a dificuldade na aprendizagem da matemática provoca fortes sentimentos de rejeição nos alunos". Para alguns, um passado de insucessos em Matemática nos leva a construir uma baixa autoestima, ocasionando sentimento de incapacidade. Lorenzato (2008) cita que a Matemática é a principal causadora da exclusão escolar, seja por evasão ou repetência, causando assim uma aversão à disciplina de modo que muitas pessoas, ao longo da vida, acabam procurando carreiras profissionais que não usam a Matemática, aumentando assim as crendices e preconceitos referentes a ela.

As dificuldades do ensino e aprendizagem de Matemática possuem outros argumentos negativos, além de sua rejeição. A desmotivação para aprender é outro fator que influencia de forma negativa. Nicolete et al. (2016) apontam que resultados preocupantes obtidos nas escolas referentes ao ensino da Matemática estão relacionados à desmotivação dos alunos, essencialmente pelo método de ensino que privilegia a memorização de procedimentos e sua aplicação em exercícios de repetição.

Neste sentido, a motivação para aprender é tema relevante. Campos (2011) afirma que 
o estudo da motivação humana representa, para o educador, uma necessidade primordial, na medida em que os métodos de ensino e aprendizagem devem considerar as individualidades dos alunos.

Lourenço e Paiva (2010) afirmam que um aluno motivado adota uma postura ativa no processo de aprendizagem, realizando tarefas desafiadoras, despendendo esforços, realizando tarefas com entusiasmo e sentindo-se realizado com seu desempenho.

Enquanto isso, Martinelli (2014) cita que estudos realizados nas últimas décadas demonstram que a motivação tem forte influência no desempenho escolar por reforçar atitudes e comportamentos que auxiliam o processo de aprendizagem tais como: prestar atenção, persistência e esforço.

A relação entre a motivação e a ABP é mostrada nos estudos de Bartscher, Gould e Nutter (1995) que relatam a utilização da ABP em salas de aulas com baixa motivação e pouca participação dos alunos, de forma que o aumento da motivação dos alunos foi comprovado pela grande parcela de alunos que passaram a completar os trabalhos de casa. Da mesma maneira, Marin et al. (2010, p. 16) mostram que "na ótica dos estudantes, tais métodos, por partirem de situações reais ou se aproximarem da realidade, estimulam o estudo constante, a independência e a responsabilidade do aluno".

No aspecto aprendizagem, Karaçalli e Korur (2014) relatam que a utilização da ABP em um curso de Ciências para um projeto relacionado a eletricidade alcançou um melhor resultado e a melhor apreensão de conhecimento do que em uma classe no qual foi aplicado o método tradicional de ensino.

Portanto, este trabalho tem por objetivo investigar, dentro do contexto educacional brasileiro, os efeitos motivacionais e de aprendizagem que o uso de um método ativo, neste caso a ABP, promoveu nos alunos sujeitos da pesquisa.

\section{Metodologia}

Este trabalho foi realizado no ano de 2017 em uma escola pública estadual de Ensino Médio localizada no município de Barra Mansa - RJ, com setenta e seis alunos, divididos em duas turmas de trinta e oito alunos, da primeira série do Ensino Médio. A faixa etária dos alunos está entre catorze e dezessete anos de idade. É importante destacar que o pesquisador também era o professor das duas turmas de aplicação.

Foi adotada uma abordagem quantitativa por meio de um delianeamento de pesquisa experimental de medidas repetidas. O objetivo desta abordagem foi comparar, por meio de 
teste de hipótese estatística, eventuais diferenças entre o método de ensino tradicional e a $\mathrm{ABP}$, nos quesitos motivação para aprender, atitudes em relação a Matemática e desempenho escolar. Logo, denominou-se as turmas como A e B, sendo adotado como grupo experimental no primeiro bimestre do ano letivo, a turma A e como grupo de controle, a turma B. No segundo bimestre, a turma A foi o grupo de controle e a turma B, o grupo experimental. A Figura 1 ilustra a metodologia de coleta de dados utilizada.

A adoção deste método de pesquisa é justificada por Sampieri, Collado e Lucio (2013) que citam duas vantagens da adição do teste prévio em uma pesquisa. A primeira vantagem é que o teste prévio avalia o quanto foi adequada a condição inicial e a segunda vantagem é permitir analisar o ganho de cada grupo. Dancey e Reidy (2013) argumentam que a fim de se evitar efeitos de ordem na manipulação das variáveis é conveniente introduzir um contrabalanço no estudo. Ou seja, metade dos participantes participa de uma condição e a outra metade não participa, depois se repete o procedimento com inversão de cada metade, ou seja, procedimento adotado neste trabalho.

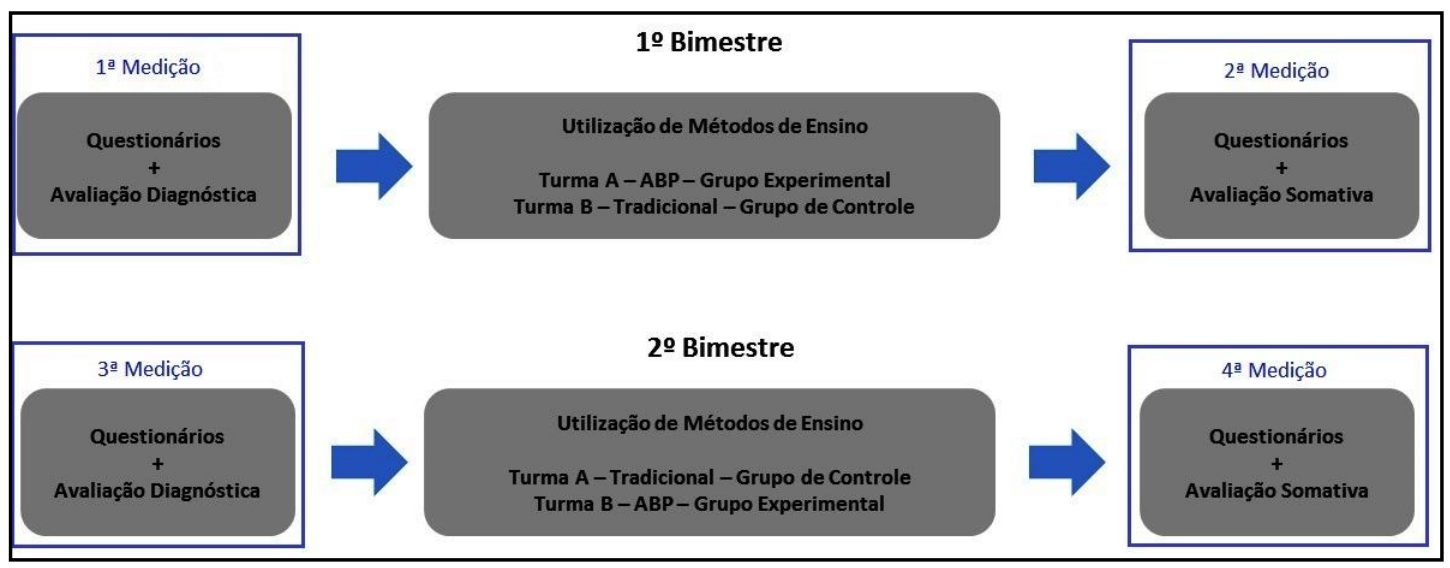

Figura 1 - Metodologia de pesquisa quantitativa Fonte: Elaborado pelos autores (2017).

Para a coleta de dados sobre a motivação para aprender, foi utilizado o instrumento Escala de Avaliação da Motivação para Aprender de Alunos do Ensino Médio (EMA-EM) adaptada por Marchiore e Alencar (2009), a partir de uma versão para o Ensino Fundamental desenvolvida por Neves e Boruchovitch (2007) denominada Escala de Avaliação da Motivação para Aprender de Alunos do Ensino Fundamental (EMA-EF).

O instrumento EMA-EM é composto por trinta e uma perguntas a serem respondidas em uma escala Likert de três pontos; nunca, às vezes e sempre. No presente estudo, após um teste piloto com os alunos, as alternativas da escala Likert foram modificadas para discordo, não concordo e nem discordo e discordo. O instrumento EMA-EM possui amplitude de 62 pontos, com valor mínimo de 31 pontos e valor máximo de 93 pontos e tem como objetivo 
avaliar as atitudes dos alunos em dois fatores motivacionais: motivação intrínseca e motivação extrínseca.

Aplicou-se o instrumento EMA-EM no início e término de cada bimestre nas duas turmas. A Tabela 1 apresenta o coeficiente alfa de Cronbach, para avaliar a consistência interna do questionário, para o instrumento EMA-EM. O alfa de Cronbach é uma medida da fiabilidade do questionário, isto é da capacidade do mesmo ser consistente. Em outras palavras, devemos esperar resultados semelhantes quando um instrumento fiável é aplicado em grupos semelhantes de pessoas. Um alfa adequado é de pelo menos 0,7 . Valores de alfa muito baixos podem indicar uma codificação errada dos itens do questionário, ou ainda, itens que medem dimensões diferentes, exigindo assim uma reavaliação das perguntas.

Tabela 1 - Alfa de Cronbach para a escala EMA-EM

\begin{tabular}{lcccc}
\hline & \multicolumn{2}{c}{$\mathbf{1}^{\mathbf{0}}$ Bimestre } & \multicolumn{2}{c}{$\mathbf{2}^{\mathbf{0}}$ Bimestre } \\
& Pré-teste & Pós-teste & Pré-teste & Pós-teste \\
\hline \multirow{2}{*}{ Turma A } & 0,771 & 0,873 & 0,856 & 0,868 \\
& 0,851 & 0,916 & 0,911 & 0,908 \\
\hline
\end{tabular}

Fonte: Elaborado pelos autores (2017).

Conforme a Tabela 2 os resultados da Tabela 1 mostram que o questionário apresentou uma consistência interna entre Aceitável a Excelente.

Tabela 2 - Consistência interna do questionário segundo o valor de alfa de Cronbach.

\begin{tabular}{|c|c|}
\hline Valor de alfa & Consistência Interna \\
\hline$[0,91 ; 1]$ & Excelente \\
\hline$[0,81 ; 0,91)$ & Bom \\
\hline$[0,71 ; 0,81)$ & Aceitável \\
\hline$[0,61 ; 0,71)$ & Questionável \\
\hline$[0,51 ; 0,61)$ & Pobre \\
\hline$[0 ; 0,51)$ & Inaceitável \\
\hline
\end{tabular}

Fonte: Adaptado de George e Mallery (2003)

Para coleta de dados sobre as atitudes em relação à Matemática, utilizou-se o instrumento denominado Escala de Atitudes em Relação à Matemática (EARM) desenvolvido por Brito (1998). Segundo a autora este instrumento foi adaptado às condições brasileiras pela própria a partir de uma escala desenvolvida por Aiken (1961, apud Brito, 1998) considerada, segundo a autora, uma das mais conhecidas escalas de atitudes em relação a Matemática.

O instrumento EARM é composto por vinte perguntas de forma a exprimir os sentimentos positivos e negativos dos alunos em relação à Matemática e serem respondidos em uma escala Likert de quatro pontos; discordo totalmente, discordo, concordo e concordo totalmente. Para a análise dos resultados fornecidos pela escala os sentimentos positivos tiveram atribuídos uma pontuação de ordem crescente; 1 (discordo totalmente), 2 (discordo), 
3 (concordo) e 4 (concordo totalmente). Os sentimentos negativos tiveram os pontos atribuídos em sentido contrário. Desse modo, os sujeitos com maior pontuação tem uma atitude positiva em relação a Matemática. Da mesma forma que no instrumento anterior, aplicou-se o instrumento EARM no início e término de cada bimestre nas duas turmas. A Tabela 3 apresenta o coeficiente alfa de Cronbach para o instrumento EARM com excelentes resultados, assim como o já exposto na Tabela 2.

Para coleta de dados referente ao desempenho escolar foram utilizadas avaliações a partir de questões de Matemática oriundas de provas anteriores e simulados da Prova Brasil.

Tabela 3 - Alfa de Cronbach para a escala EARM

\begin{tabular}{ccccc}
\hline & \multicolumn{2}{c}{$\mathbf{1}^{\mathbf{0}}$ Bimestre } & \multicolumn{2}{c}{$\mathbf{2}^{\mathbf{0}}$ Bimestre } \\
& Pré-teste & Pós-teste & Pré-teste & Pós-teste \\
\hline \multirow{2}{*}{ Turma A } & 0,933 & 0,938 & 0,928 & 0,955 \\
& & & 0,975 & 0,974 \\
Turma B & 0,956 & 0,965 & 0,95 & \\
& & & & \\
\hline
\end{tabular}

Fonte: Elaborado pelos autores (2017).

As avaliações foram denominadas diagnóstica e somativa e utilizadas respectivamente como pré-teste e pós-teste em cada um dos bimestres. As questões utilizadas nessas avaliações foram selecionadas a partir da matriz de referência da Prova Brasil que define descritores para determinada habilidade ou competência. Conforme o Plano de Desenvolvimento da Educação (BRASIL, 2008), as matrizes de Matemática estão estruturadas por anos e séries avaliadas. Assim, os descritores indicam uma determinada habilidade que deve ser desenvolvida nesta fase de ensino. No PDE (BRASIL, 2008, p. 1) determina-se que "os descritores não contemplam todos os objetivos de ensino, mas apenas aqueles considerados mais relevantes e possíveis de serem mensurados em uma prova" de modo a "obter informações que forneçam uma visal real do ensino".

O motivo da escolha de questões da Prova Brasil e descritores do Ensino Fundamental para avaliação de conteúdo escolar aos alunos do Ensino Médio foi devido aos alunos serem recém ingressos no Ensino Médio, o que torna possível mensurar os conhecimentos prévios dos alunos no início do bimestre e posteriormente mensurar como esses conhecimentos prévios evoluíram ao longo do bimestre letivo. Os descritores avaliados no primeiro bimestre são mostrados no Quadro 1 e foram selecionados conforme conteúdos curriculares previstos pela Secretaria de Educação (BRASIL, 2008). 


\begin{tabular}{|l|c|}
\hline \multicolumn{1}{|c|}{ Descritores avaliados no 10 bimestre } & \multicolumn{1}{|c|}{$\begin{array}{c}\text { 9 } \\
\text { Ensino } \\
\text { Fundamental }\end{array}$} \\
\hline Resolver problema envolvendo o cálculo de perímetro de figuras planas. & D-12 \\
\hline Resolver problema envolvendo o cálculo de área de figuras planas. & D-13 \\
\hline $\begin{array}{l}\text { Identificar a localização de números racionais na reta numérica. } \\
\text { operações (adição, subtração, multiplicação, divisão, potenciação). }\end{array}$ & D-17 significados das \\
\hline $\begin{array}{l}\text { Resolver problema com números inteiros envolvendo as operações (adição, subtração, } \\
\text { multiplicação, divisão, potenciação). }\end{array}$ & D-20 \\
\hline $\begin{array}{l}\text { Identificar frações equivalentes. } \\
\text { Efetuar cálculos que envolvam operações com números racionais (adição, subtração, } \\
\text { multiplicação, divisão, potenciação). }\end{array}$ & D-23 \\
\hline $\begin{array}{l}\text { Resolver problema que envolva porcentagem. } \\
\text { Resolver problema que envolva variação proporcional, direta ou inversa, entre } \\
\text { grandezas. }\end{array}$ & D-28 \\
\hline
\end{tabular}

Quadro 1 - Descritores utilizados para avaliações de conteúdo. Fonte: Elaborados pelos autores (2017).

Exemplificando os descritores utilizados nas avaliações diagnóstica e somativa do primeiro bimestre, a Figura 2 apresenta duas questões com o mesmo descritor, D-17, que consiste na habilidade de identificar a localização de números racionais na reta numérica.

\section{Avaliação Diagnóstica}

1. Na reta numérica da figura abaixo, o ponto $\mathrm{E}$ corresponde ao número inteiro $-9 \mathrm{e}$ o ponto $\mathrm{F}$, ao inteiro - 7. (D-17)

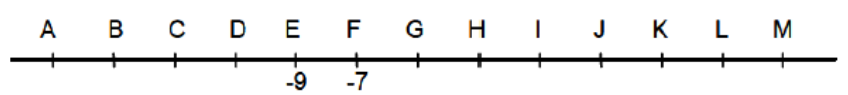

Nesta reta o ponto correspondente ao número zero estará na posição:

Avaliação Somativa

1. A figura abaixo mostra os pontos $P$ e $Q$ que correspondem a números racionais e foram posicionados na reta numerada do conjunto dos números racionais. (D-17)

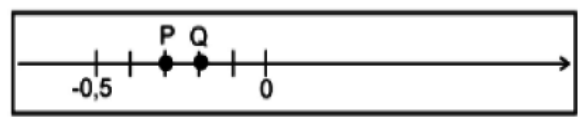

Os valores atribuídos a $\mathrm{P}$ e Q conforme suas posições na reta numérica são:

Figura 2 - Questão utilizando o descritor D-17

Fonte: Elaborado pelos autores (2017).

Os descritores avaliados no segundo bimestre são mostrados no Quadro 2 e foram selecionados conforme conteúdos curriculares previstos pela Secretaria de Educação (BRASIL, 2008). 


\begin{tabular}{|c|c|}
\hline Descritores avaliados no $2^{\circ}$ bimestre & $\begin{array}{c}9^{\circ} \text { Ano } \\
\text { Ensino } \\
\text { Fundamental } \\
\end{array}$ \\
\hline $\begin{array}{l}\text { Identificar a localização/movimentação de objeto em mapas, croquis e outras } \\
\text { representações gráficas. }\end{array}$ & D-1 \\
\hline Interpretar informações apresentadas por meio de coordenadas cartesianas. & D-9 \\
\hline Identificar a localização de números inteiros na reta numérica. & D-16 \\
\hline Identificar a localização de números racionais na reta numérica. & D-17 \\
\hline Identificar uma equação ou inequação do $1^{\circ}$ grau que expressa um problema. & D-33 \\
\hline $\begin{array}{l}\text { Identificar a relação entre as representações algébrica e geométrica de um sistema de } \\
\text { equações do } 1^{\circ} \text { grau. }\end{array}$ & D-35 \\
\hline Resolver problema envolvendo informações apresentadas em tabelas e/ou gráficos. & D-36 \\
\hline $\begin{array}{l}\text { Associar informações apresentadas em listas e/ou tabelas simples aos gráficos que as } \\
\text { representam e vice-versa. }\end{array}$ & D-37 \\
\hline
\end{tabular}

Quadro 2 - Descritores utilizados para avaliações de conteúdo Fonte: Elaborado pelos autores (2017).

Exemplificando os descritores utilizados nas avaliações diagnóstica e somativa do segundo bimestre, a Figura 3 apresenta duas questões com o mesmo descritor, D-1, que consiste na habilidade de identificar a localização/movimentação de objeto em mapas, croquis e outras representações gráficas.

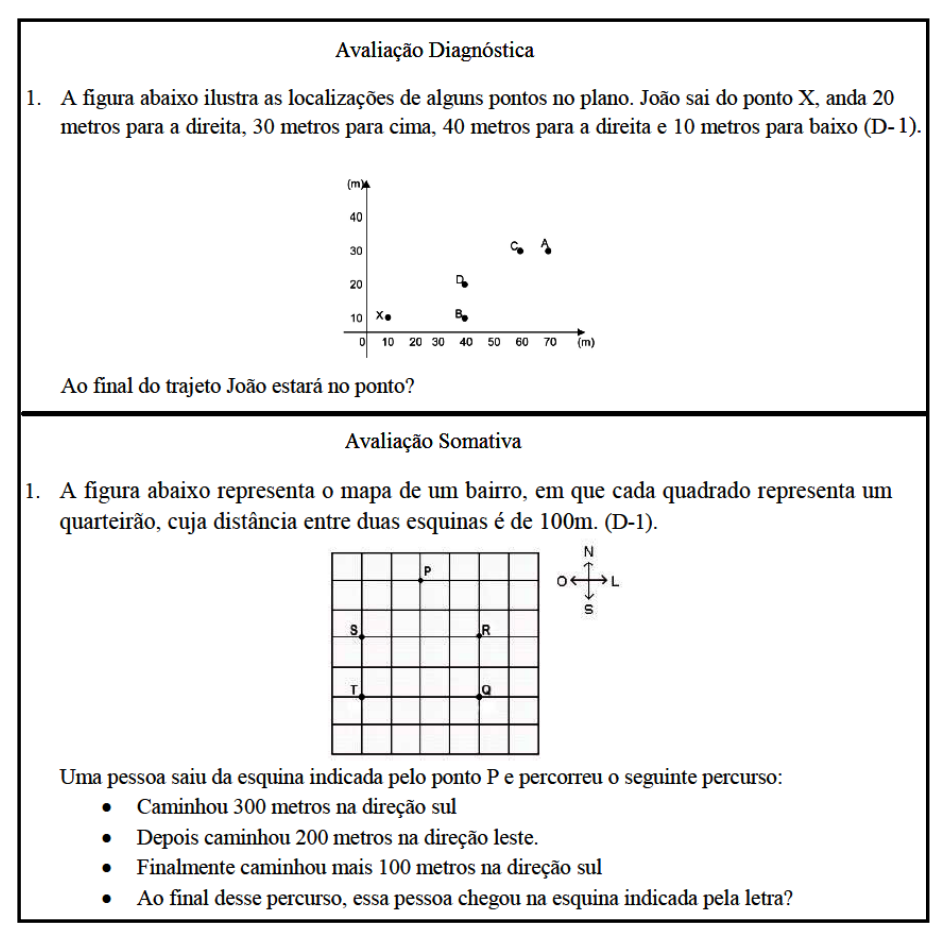

Figura 3 - Questão utilizando o descritor D-1

Fonte: Elaborado pelos autores (2017). 


\section{Resultados}

Os resultados serão apresentados divididos em quatro subseções; Projetos realizados; Motivação para aprender; Atitude em relação a Matemática; e Avaliação de conteúdos curriculares. Na primeira destas subseções serão descritos os objetivos dos projetos e da segunda até a quarta subseções serão apresentados os dados descritivos e os resultados dos testes estatísticos.

Utilizou-se para análise dos dados estatísticos o software SPSS versão 20.0. Cabe ressaltar que o número de alunos variou no decorrer dos dois bimestres em que a pesquisa foi realizada devido a evasão e licenças médicas dos alunos. Além disso, foi utilizado para os testes estatísticos, como variável independente (VI), o método de ensino e como variáveis dependentes (VD) a motivação para aprender, a atitude em relação à Matemática e o desempenho acadêmico. Adotou-se como hipótese nula que não existem diferenças significativas entre os métodos de ensino nos três aspectos citados.

\subsection{Projetos realizados}

Foram realizados dois projetos a partir da $\mathrm{ABP}$ com as turmas. $\mathrm{O}$ primeiro projeto, denominado Planta baixa da escola, foi realizado no primeiro bimestre e consistiu na sugestão de melhoria em algum ambiente da escola relacionado à infraestrutura predial. Os produtos finais a serem apresentados à comunidade escolar deveriam incluir as plantas baixas dos ambientes, o quantitativo de material e a planilha de orçamento.

As atividades ocorreram durante as aulas de Matemática. Desse modo, durante seis semanas, os alunos tiveram disponíveis duas aulas semanais para as atividades do projeto. $\mathrm{O}$ professor orientou os alunos durante as medições, cálculo de área, perímetro, estimativa de gastos e cálculos dos orçamentos. O produto final poderia ser uma apresentação em slides ou vídeos. Destacamos o produto final de uma das equipes que confeccionou um vídeo de curta duração mostrando o desenvolvimento do projeto da equipe.

O segundo projeto denominado Utilizando funções na economia de energia elétrica, foi realizado no segundo bimestre pela turma B. Neste projeto, os alunos, também divididos em equipes, deveriam coletar em suas casas dados de potência elétrica de eletrodomésticos, efetuar o cálculo de consumo diário, estimar por meio de uma função afim o consumo mensal e apresentar a comunidade escolar dicas e sugestões para uso consciente de energia elétrica.

Uma das equipes produziu como produto final do projeto, uma planilha de cálculo 
automático de consumo de energia elétrica disponível na internet e um vídeo explicativo de como utilizar esta planilha. Ressalta-se a criatividade da equipe ao tornar sua planilha acessível a todos.

\subsection{Motivação para aprender}

A Figura 4 apresenta por meio de diagrama de caixa e bigode a distribuição de frequência para o instrumento EMA-EM em quatros aplicações no decorrer do estudo. Destaca-se no diagrama apresentado a existência de dados atípicos, círculos com números associados, que representam alunos com baixa motivação em relação aos demais. Esses dados são relevantes na medida em que indicou, com certa antecedência, alunos que evadiram. Por exemplo, na Turma A no $1^{\circ}$ bimestre, o número 31 , refere-se a um aluno evadido no $1^{\circ}$ bimestre. E na turma B, os números 50 e 66, 126 e 142, referem-se respectivamente a dois alunos com baixa motivação que evadiram no decorrer do $2^{\circ}$ bimestre.

A seguir, verificamos por meio do teste de Shapiro-Wilk a normalidade dos dados coletados para as VD. Segundo Yap e Sim (2011), o teste Shapiro-Wilk é o teste de normalidade mais poderoso entre os algoritmos disponíveis de modo a garantir a correta utilização dos métodos de teste de hipóteses estatísticas. O teste de Shapiro-Wilk garante a normalidade da distribuição de frequência dos dados quando apresenta um nível de significância maior que 0,05 .

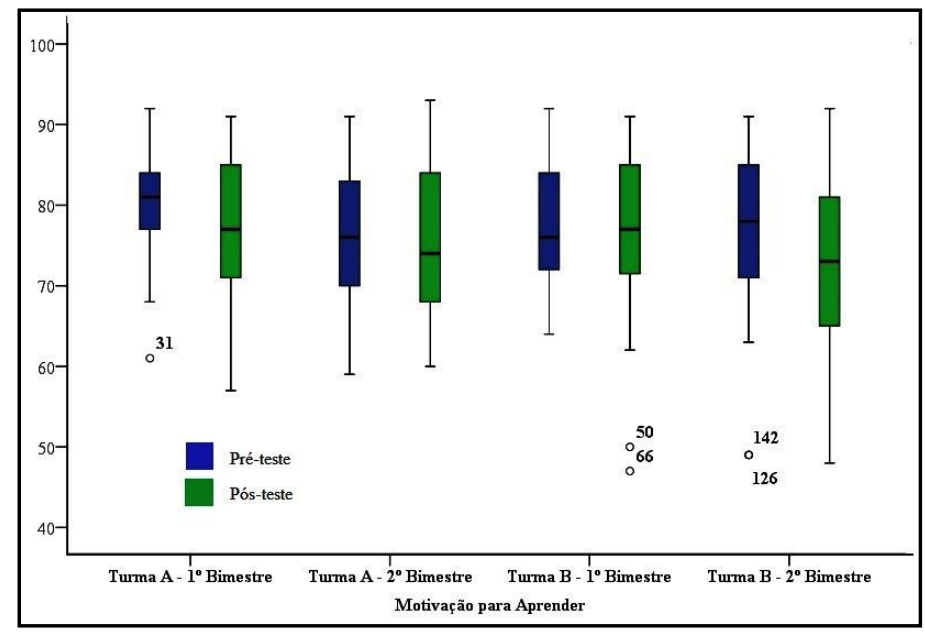

Figura 4 - Motivação para aprender (EMA-EM)

Fonte: Elaborado pelos autores (2017).

A Tabela 4 apresenta os resultados do teste de normalidade nos quatro momentos da aplicação do instrumento EMA-EM e respectivos testes estatísticos utilizados. 
Tabela 4 - Teste Shapiro-Wilk para o instrumento EMA-EM

\begin{tabular}{cccccc}
\hline & \multicolumn{2}{c}{$\mathbf{1}^{\mathbf{0}}$ Bimestre } & & \multicolumn{2}{c}{$\mathbf{2}^{\mathbf{o}}$ Bimestre } \\
& Pré-teste & Pós-teste & & Pré-teste & Pós-teste \\
\hline \multirow{2}{*}{ Turma A } & 0,133 & 0,446 & Turma A & 0,515 & 0,351 \\
Turma B & 0,225 & 0,028 & Turma B & 0,004 & 0,888 \\
Teste Utilizado & t de Student & Mann-Whitney & & Mann-Whitney & t de Student \\
& & & & & \\
\hline
\end{tabular}

Fonte: Elaborado pelos autores (2017).

Devido a não normalidade de dados na turma B no pós-teste do $1^{\circ}$ bimestre e pré-teste do $2^{\circ}$ bimestre foi utilizado o teste não paramétrico Mann-Whitney nesses momentos.

No pré-teste do primeiro bimestre ao se executar o teste $t$ independente, os alunos da turma $\mathrm{A}(\mathrm{M}=80,47, \mathrm{DP}=6,38)$ obtiveram resultados (média) ligeiramente maiores do que os alunos da turma $\mathrm{B}(\mathrm{M}=77,39, \mathrm{DP}=8,11)$, no qual a diferença entre as médias foi de 3,08 . $\mathrm{O}$ intervalo $95 \%$ de confiança para a diferença estimada das médias obtidas é 0,29 a 6,46. O teste $t$ independente revelou que não devemos rejeitar a hipótese nula $(\mathrm{t}(72)=1,82$; valor-p $=$ 0,072). Ou seja, não foi observada diferença significativa entre as turmas.

No pós-teste do primeiro bimestre, utilizamos devido a assimetria dos dados, o equivalente não paramétrico ao teste $t$ independente que é o teste Mann-Whitney. Os alunos da turma A (mediana $=77)$ parecem não diferir dos alunos da turma B (mediana $=78$ ) em relação a motivação para aprender. $O$ valor $U$ de Mann-Whitney foi 665,5 ( $z=-0,206)$ com valor de probabilidade associada de 0,84 .

A Figura 5 apresenta os diagramas de barra do pré-teste e pós-teste dos dados referentes ao primeiro bimestre. Desse modo, os resultados indicam que não foi observado diferença na motivação para aprender entre a ABP e o método tradicional de ensino.

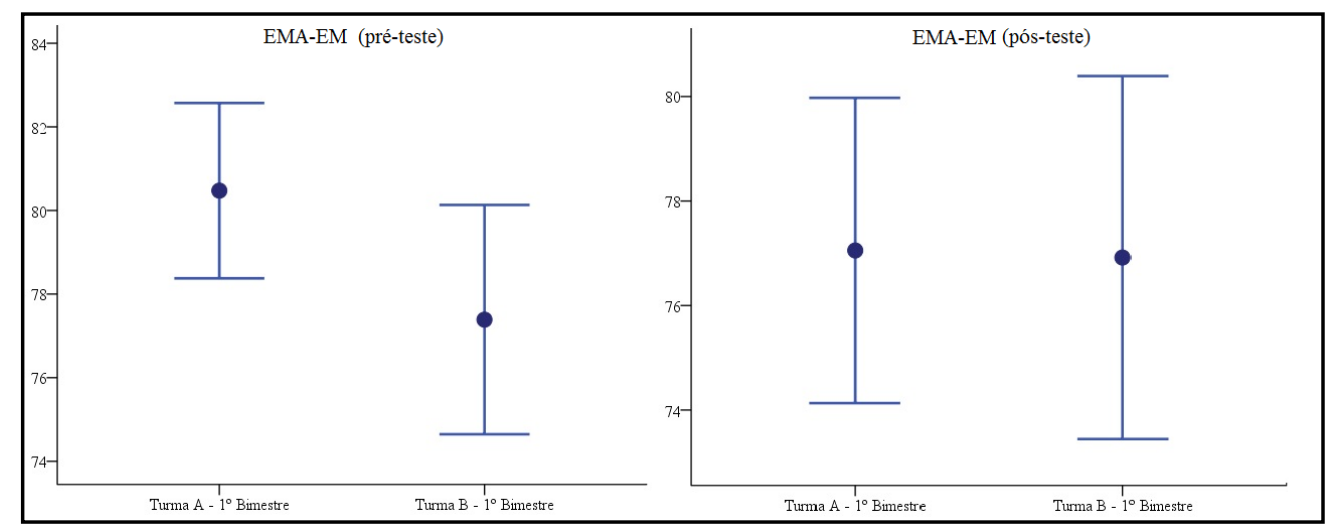

Figura 5 - EMA-EM - $1^{\circ}$ bimestre

Fonte: Elaborado pelos autores (2017).

No pré-teste do segundo bimestre, o teste de Mann-Whitney apresentou que os alunos da turma $\mathrm{A}$ (mediana $=76)$ parecem não diferir dos alunos da turma $\mathrm{B}$ (mediana $=78$ ). $\mathrm{O}$ 
valor U de Mann-Whitney foi $591(\mathrm{z}=-0,829)$ com probabilidade associada 0,41 , sugerindo a inexistência de diferença entre as turmas.

No pós-teste do segundo bimestre, o teste $t$ de Student independente apresentou que a turma $\mathrm{A}(\mathrm{M}=75,29, \mathrm{DP}=8,77)$ teve uma média ligeiramente maior que os alunos da turma $\mathrm{B}$ $(\mathrm{M}=72,54, \mathrm{DP}=10,44)$. A diferença entre as médias foi 2,75 . O intervalo foi de $95 \%$ de confiança para a diferença estimada das médias obtidas foi 1,83 a 7,34. O teste $t$ sugere que não foi observada diferença significativa entre as turmas $(\mathrm{t}(69)=1,20$; valor- $\mathrm{p}=0,235)$.

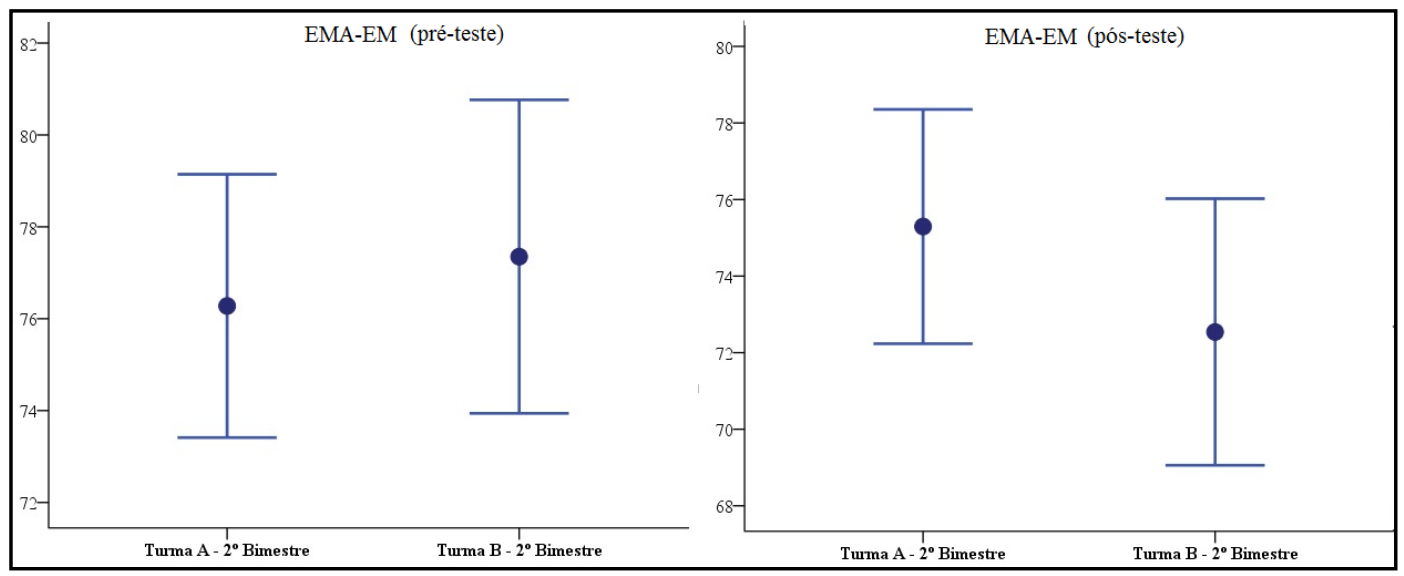

Figura 6 - EMA-EM $-2^{\circ}$ bimestre

Fonte: Elaborado pelos autores (2017).

A Figura 6 apresenta os diagramas de barra do pré-teste e pós-teste dos dados referentes ao segundo bimestre. Desse modo, os resultados indicam que não foi observado diferença significativa na motivação para aprender entre a $\mathrm{ABP}$ e o método tradicional de ensino.

Do mesmo modo, a Tabela 6 apresenta o resumo dos testes estatísticos efetuados a partir dos dados coletados das aplicações do instrumento EMA-EM, ratificando que não foi observada diferença significativa entre os métodos de ensino tradicional e ABP no aspecto motivação para aprender.

Tabela 6 - Resultados - motivação para aprender

\begin{tabular}{ccccccc}
\hline & Pré-teste & $\begin{array}{c}\mathbf{1}^{\mathbf{o}} \text { Bimestre } \\
\text { Método de Ensino }\end{array}$ & Pós-teste & Pré-teste & Método de Ensino & Pós-teste \\
\hline \multirow{2}{*}{ Turma A } & $\mathrm{O}_{1}$ & $\mathrm{ABP}$ & $\mathrm{O}_{2}$ & $\mathrm{O}_{5}$ & Tradicional & $\mathrm{O}_{6}$ \\
Turma B & $\mathrm{O}_{3}$ & Tradicional & $\mathrm{O}_{4}$ & $\mathrm{O}_{7}$ & $\mathrm{ABP}$ & $\mathrm{O}_{8}$ \\
& & $\mathrm{O}_{1}=\mathrm{O}_{3} \mathrm{e} \mathrm{O}_{2}=\mathrm{O}_{4}$ & & & $\mathrm{O}_{5}=\mathrm{O}_{7}$ e $\mathrm{O}_{6}=\mathrm{O}_{8}$ \\
\hline
\end{tabular}

Fonte: Elaborado pelos autores a partir de Sampieri, Collado e Lucio (2013).

\subsection{Atitudes em relação à Matemática}

A partir da Figura 7 que apresenta a distribuição de frequência referente ao 
instrumento EARM, destacamos uma grande dispersão dos dados já a partir do primeiro bimestre e o aumento no decorrer dos bimestres letivos. Esta dispersão de dados indica que os alunos pertencentes as turmas objetos de pesquisa, apresentam atitudes bastante heterogêneas em relação à Matemática. $\mathrm{O}$ aumento da amplitude pode ter sido causado por dificuldades de alguns alunos com os conteúdos programáticos que serão objetos de futuros estudos.

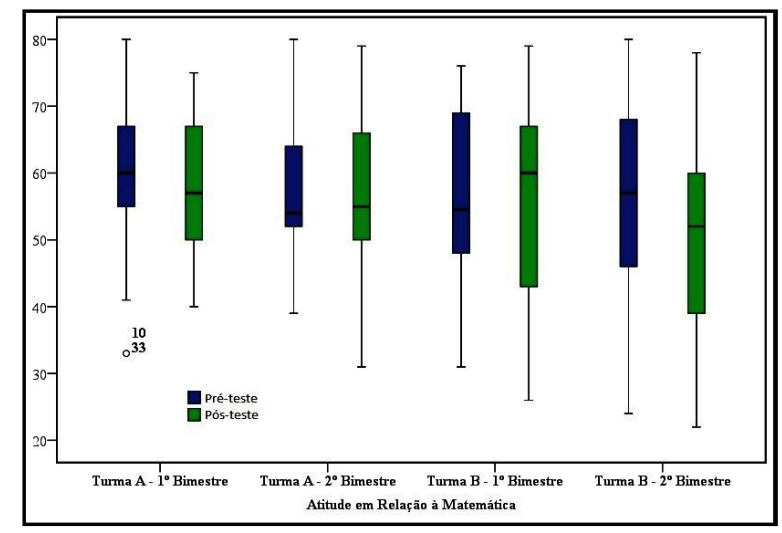

Figura 7 - Atitude em relação à Matemática (EARM) Fonte: Elaborado pelos autores (2017).

A Tabela 7 apresenta as médias $(\overline{\mathbf{x}})$ e os desvios-padrões $(\sigma)$ em formato numérico dos dados apresentados na Figura 7.

Tabela 7 - Média e desvio padrão do instrumento EARM

\begin{tabular}{|c|c|c|c|c|c|c|c|c|c|}
\hline & \multicolumn{4}{|c|}{$\mathbf{1}^{\circ}$ Bimestre } & & \multicolumn{4}{|c|}{$2^{\circ}$ Bimestre } \\
\hline & \multicolumn{2}{|c|}{ Pré-teste } & \multicolumn{2}{|c|}{ Pós-teste } & & \multicolumn{2}{|c|}{ Pré-teste } & \multicolumn{2}{|c|}{ Pós-teste } \\
\hline & $\overline{\mathbf{x}}$ & $\boldsymbol{\sigma}$ & $\overline{\mathbf{x}}$ & $\sigma$ & & $\overline{\mathbf{x}}$ & $\sigma$ & $\overline{\mathbf{x}}$ & $\sigma$ \\
\hline $\begin{array}{c}\text { Turma A } \\
(n=37)\end{array}$ & 59,71 & 10,30 & 57,76 & 10,82 & $\begin{array}{c}\text { Turma A } \\
(n=34)\end{array}$ & 55,86 & 10,30 & 56,26 & 12,31 \\
\hline $\begin{array}{c}\text { Turma B } \\
(\mathrm{n}=34)\end{array}$ & 56,37 & 12,49 & 56,24 & 14,61 & $\begin{array}{c}\text { Turma B } \\
(\mathrm{n}=37)\end{array}$ & 55,22 & 14,71 & 51,00 & 15,50 \\
\hline
\end{tabular}

Fonte: Elaborado pelos autores (2017).

Em seguida, a Tabela 8 apresenta os resultados do teste Shapiro-Wilk que indica a utilização do teste $t$ de Student em todos os quatro momentos de aplicação do instrumento EARM.

Tabela 8 - Teste Shapiro-Wilk para o instrumento EARM

\begin{tabular}{cccccc}
\hline & \multicolumn{2}{c}{$\mathbf{1}^{\mathbf{0}}$ Bimestre } & & \multicolumn{2}{c}{$\mathbf{2}^{\mathbf{0}}$ Bimestre } \\
& Pré-teste & Pós-teste & & Pré-teste & Pós-teste \\
\hline \multirow{2}{*}{ Turma A } & 0,094 & 0,067 & Turma A & 0,149 & 0,411 \\
Turma B & 0,156 & 0,133 & Turma B & 0,323 & 0,282 \\
Teste Utilizado & t de Student & t de Student & & t de Student & t de Student
\end{tabular}

Fonte: Elaborado pelos autores (2017). 
Pelos resultados apresentados nas Tabelas 7 e 8, podemos notar que, no primeiro bimestre, a aplicação do teste $t$ nos dados coletados no pré-teste apresentou que os alunos da turma A tiveram uma maior atitude em relação a Matemática $(\mathrm{M}=59,71, \mathrm{DP}=10,30)$ que os alunos da turma $\mathrm{B}(\mathrm{M}=56,37, \mathrm{DP}=12,59)$, porém essa diferença não foi significativa $(\mathrm{t}(71)$ $=1,25, \mathrm{p}=0,215)$. Enquanto isso, a aplicação do teste $t$ nos dados coletados no pós-teste apresentou que os alunos da turma A tiveram uma maior atitude em relação à Matemática $(\mathrm{M}$ $=57,76, \mathrm{DP}=10,88)$ que os alunos da turma $\mathrm{B}(\mathrm{M}=56,24, \mathrm{DP}=14,61)$, sendo que novamente essa diferença não foi significativa $(\mathrm{t}(69)=0,50, \mathrm{p}=0,618)$.

Tanto no início, quanto ao término do referido bimestre tivemos o valor de $\mathrm{p}>0,05$, logo, os resultados indicam que no primeiro bimestre não foi observado diferença significativa entre os métodos de ensino adotados nas turmas A e B. A Figura 8 ilustra a situação descrita.

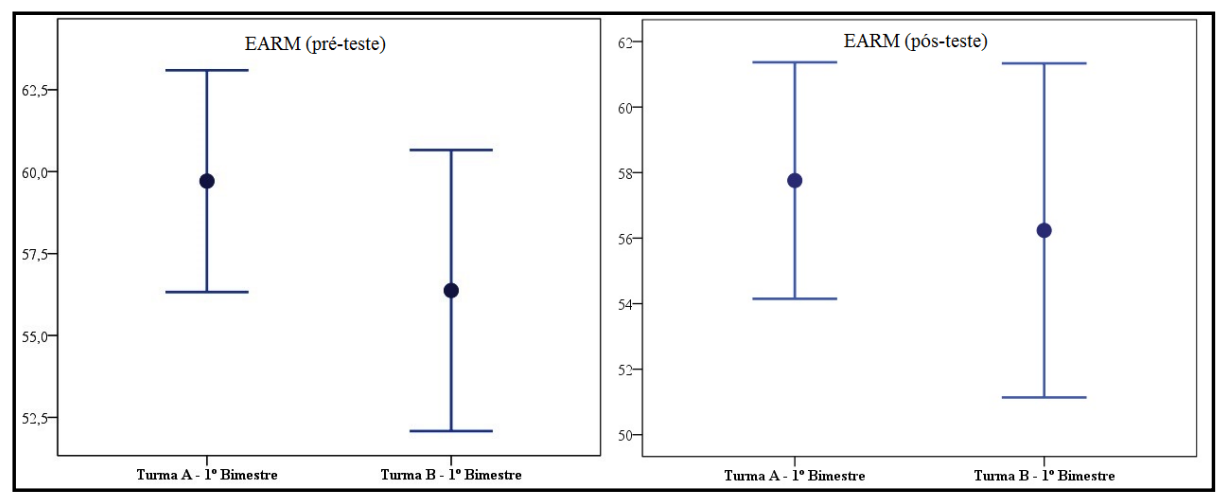

Figura 8 - EARM - $1^{\circ}$ bimestre

Fonte: Elaborado pelos autores (2017).

No segundo bimestre, os resultados do teste $t$ do pré-teste apresentaram para a turma A $(\mathrm{M}=55,86, \mathrm{DP}=10,30)$ e para a turma $\mathrm{B}(\mathrm{M}=55,22, \mathrm{DP}=14,71)$, diferença que não foi significativa $(\mathrm{t}(64)=0,217, \mathrm{p}=0,829)$. Os resultados do pós-teste indicaram para a turma $\mathrm{A}$ $(\mathrm{M}=56,26, \mathrm{DP}=2,11)$ e para a turma $\mathrm{B}(\mathrm{M}=51,00, \mathrm{DP}=2,55)$, de modo que esta diferença não foi significativa $(t(69)=1,576, p=0,120)$. A Figura 9 ilustra os resultados apresentados.

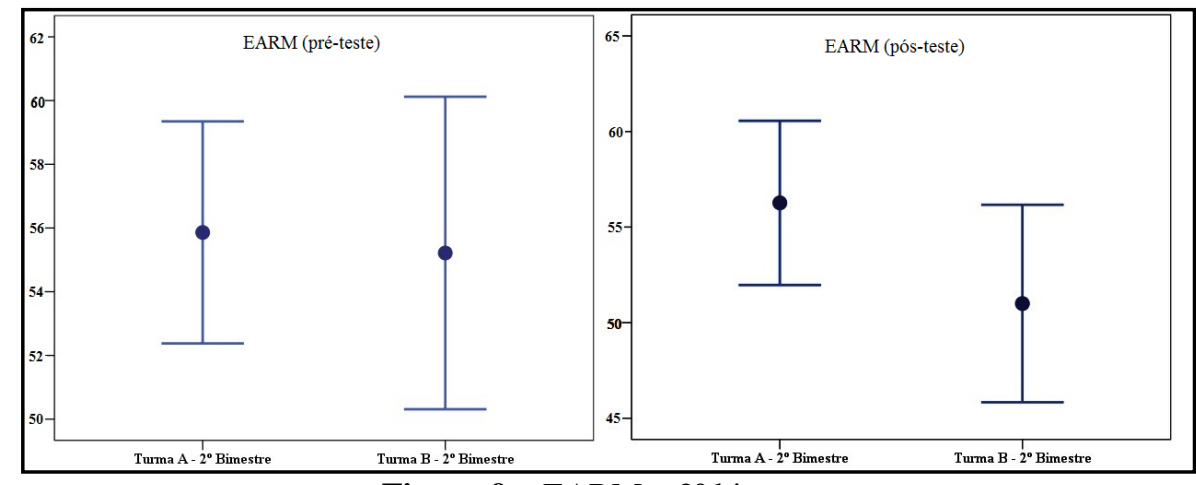

Figura 9 - EARM - $2^{\circ}$ bimestre

Fonte: Elaborado pelos autores (2017). 


\subsection{Avaliação de conteúdo curricular}

Agora com relação ao conteúdo curricular, iniciamos apresentando a Figura 10 que destaca a distribuição de frequência referente aos resultados obtidos pelos alunos nas avaliações de conteúdo. Percebe-se a grande dispersão dos valores no primeiro bimestre, tanto para a turma $\mathrm{A}$, quanto para a turma $\mathrm{B}$, o que sugere uma maior dificuldade com os conhecimentos prévios. A Tabela 9 apresenta as médias $(\bar{x})$ e desvios-padrões $(\sigma)$ em formato numérico dos dados apresentados na Figura 10.

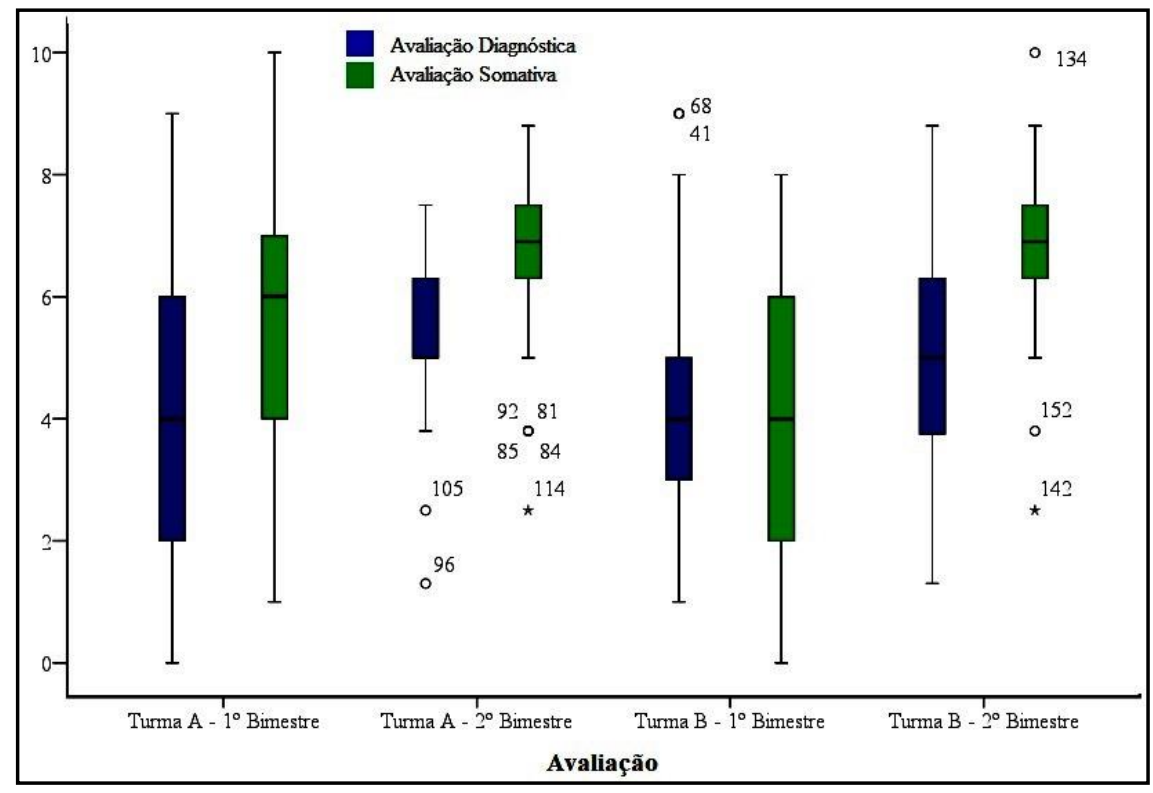

Figura 10 - Avaliações de conteúdo curricular

Fonte: Elaborado pelos autores (2017).

Tabela 9 - Média e desvio padrão das avaliações

\begin{tabular}{|c|c|c|c|c|c|c|c|c|c|}
\hline & \multicolumn{4}{|c|}{$1^{\circ}$ Bimestre } & & \multicolumn{4}{|c|}{$2^{\circ}$ Bimestre } \\
\hline & \multicolumn{2}{|c|}{ Pré-teste } & \multicolumn{2}{|c|}{ Pós-teste } & & \multicolumn{2}{|c|}{ Pré-teste } & \multicolumn{2}{|c|}{ Pós-teste } \\
\hline & $\overline{\mathbf{x}}$ & $\sigma$ & $\overline{\mathbf{x}}$ & $\sigma$ & & $\overline{\mathbf{x}}$ & $\sigma$ & $\overline{\mathbf{x}}$ & $\sigma$ \\
\hline $\begin{array}{c}\text { Turma A } \\
(n=34)\end{array}$ & 3,86 & 2,45 & 5,58 & 2,28 & $\begin{array}{c}\text { Turma A } \\
(\mathrm{n}=37)\end{array}$ & 5,24 & 1,43 & 6,62 & 1,73 \\
\hline $\begin{array}{c}\text { Turma B } \\
(n=33)\end{array}$ & 4,41 & 2,29 & 3,95 & 2,40 & $\begin{array}{l}\text { Turma B } \\
(\mathrm{n}=33)\end{array}$ & 4,97 & 1,85 & 6,70 & 1,47 \\
\hline
\end{tabular}

Fonte: Elaborado pelos autores (2017).

Em seguida, a Tabela 10 apresenta os resultados do teste Shapiro-Wilk que indica a utilização do teste Mann-Whitney em três momentos de aplicação do instrumento EARM. 


\begin{tabular}{cccccc} 
& \multicolumn{2}{c}{ Tabela 10 - Teste Shapiro-Wilk para avaliações } \\
\hline & \multicolumn{2}{c}{$\mathbf{1}^{\mathbf{0}}$ Bimestre } & \multicolumn{2}{c}{$\mathbf{2}^{\mathbf{0}}$ Bimestre } \\
& Diagnóstica & Somativa & & Diagnóstica & Somativa \\
\hline \multirow{2}{*}{ Turma A } & 0,093 & 0,281 & Turma A & 0,012 & 0,005 \\
Turma B & 0,065 & 0,023 & Turma B & 0,143 & 0,010 \\
Teste Utilizado & t de Student & Mann-Whitney & & Mann-Whitney & Mann-Whitney \\
\end{tabular}

Fonte: Elaborado pelos autores (2017).

No primeiro bimestre, para o teste de hipótese da avaliação diagnóstica utilizamos o teste $t$ de Student. Os resultados mostram que as notas obtidas pelos alunos da turma A (M = $3,86, \mathrm{DP}=2,45)$ foram menores que as notas obtidas pelos alunos da turma $\mathrm{B}(\mathrm{M}=4,41$, DP $=2,30)$ e essa diferença não foi significativa $(\mathrm{t}(67)=0,969, \mathrm{p}=0,336)$. Para o teste de hipótese da avaliação somativa utilizamos o teste de Mann-Whitney. Os resultados indicam que os alunos da turma A (mediana =6) "parecem" diferir dos alunos da turma B (mediana = 4). O valor de U de Mann-Whitney foi 414,5 ( $\mathrm{z}=-2,798)$ com probabilidade associada 0,005 sugere a existência de diferença entre as turmas. Ou seja, a turma A, no qual se utilizou a ABP, obteve um melhor desempenho que a turma B na avaliação somativa.

A Figura 11 apresenta de forma gráfica os resultados obtidos no pré-teste e pós-teste.

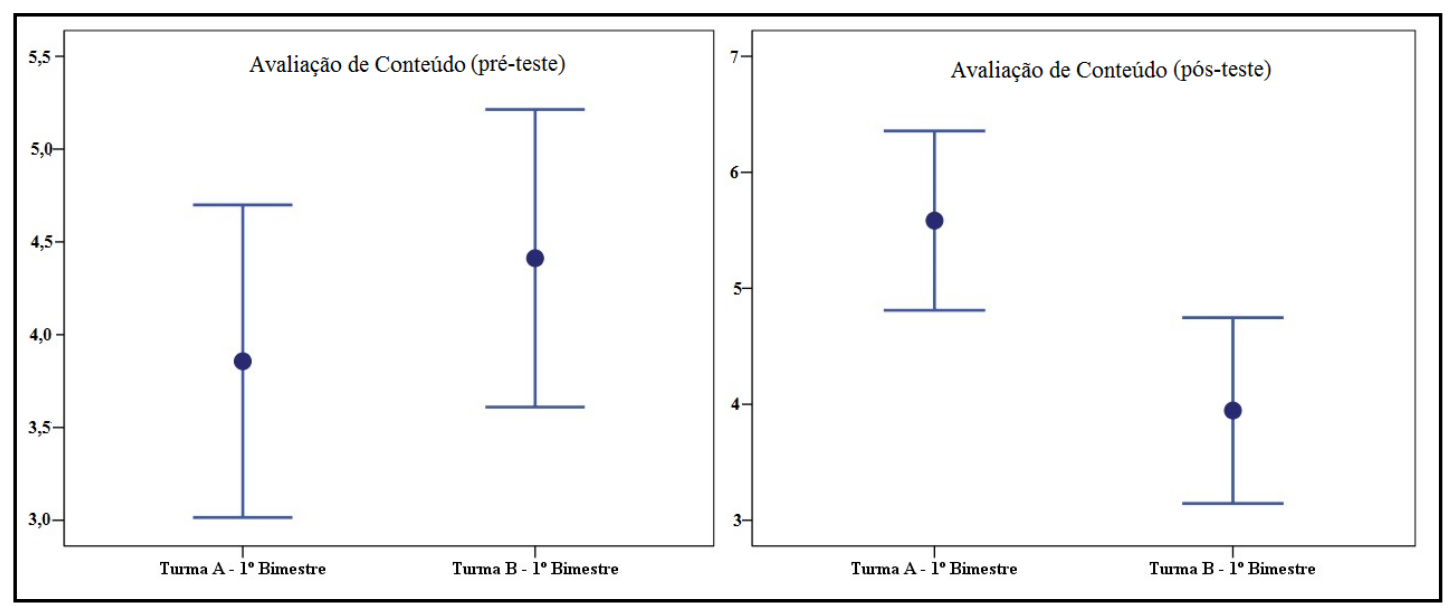

Figura 11 - Avaliação de conteúdo - $1^{\circ}$ bimestre Fonte: Elaborado pelos autores (2017).

No segundo bimestre, para a avaliação diagnóstica, o teste utilizado foi o MannWhitney. Os resultados indicam que as notas dos alunos da turma A (mediana =5) parecem não diferir das notas dos alunos da turma $\mathrm{B}$ (mediana $=5$ ). $\mathrm{O}$ valor $\mathrm{U}$ de Mann-Whitney foi $573,5(\mathrm{z}=-1,042)$ com probabilidade associada 0,298. Portanto, não foi observada diferença entre as turmas. Para avaliação somativa, o resultado do teste de Mann-Whitney indicam que os alunos da turma $\mathrm{A}$ (mediana $=6,9$ ) parecem não diferir das notas dos alunos da turma $\mathrm{B}$ (mediana $=6,9)$. O valor $\mathrm{U}$ de Mann-Whitney foi $607(\mathrm{z}=-0,061)$ com probabilidade 
associada 0,951. A Figura 12 mostra de forma gráfica os resultados citados.

A Tabela 11 apresenta os resultados para os testes de hipóteses efetuados. A única diferença significativa apresentada foi na avaliação somativa do primeiro bimestre no qual a turma A, que sofreu o tratamento experimental, teve melhor desempenho que o grupo de controle, turma B. Ou seja, os resultados indicam que a turma na qual foi utilizado a ABP como método de ensino teve um aprendizado do conteúdo ministrado melhor do que a turma na qual foi adotado o método de ensino expositivo tradicional.

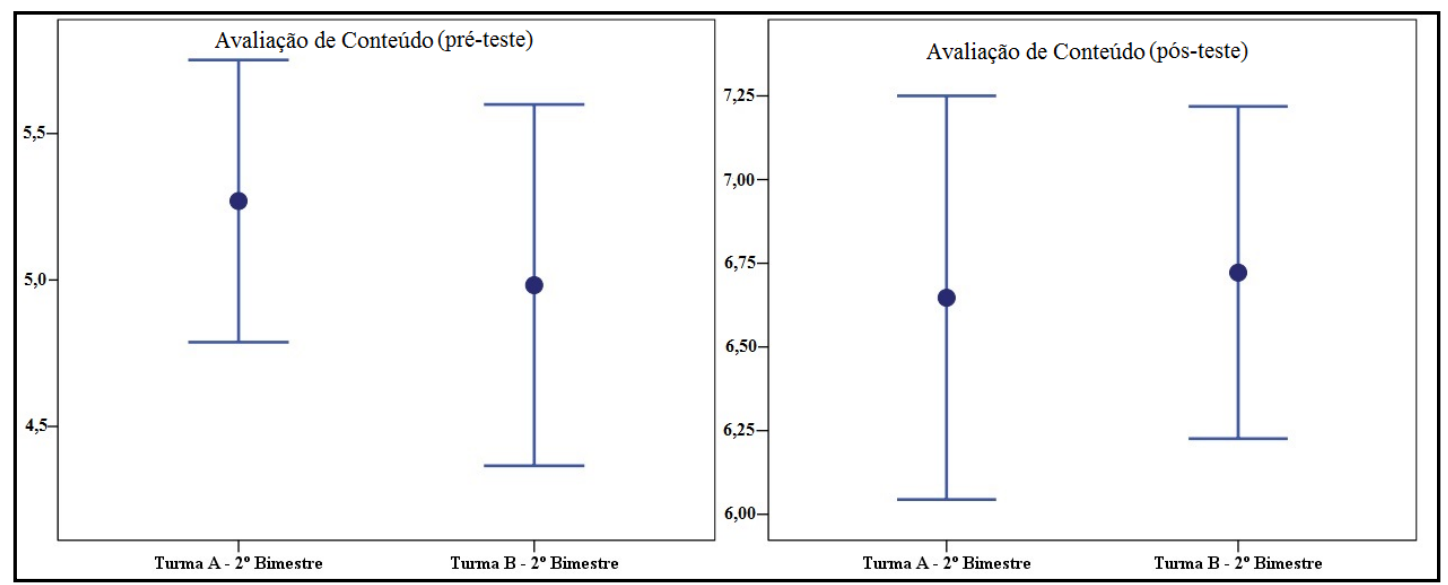

Figura 12 - Avaliação de conteúdo - $2^{\circ}$ bimestre

Fonte: Elaborado pelos autores (2017).

Tabela 11 - Resultados - desempenho escolar

$1^{\circ}$ Bimestre $\quad 2^{\circ}$ Bimestre

Diagnóstica Método de Ensino Somativa Diagnóstica Método de Ensino Somativa

$\begin{array}{lllllll}\text { Turma } \mathrm{A} & \mathrm{O}_{1} & \mathrm{ABP} & \mathrm{O}_{2} & \mathrm{O}_{5} & \text { Tradicional } & \mathrm{O}_{6}\end{array}$

$\begin{array}{lllllll}\text { Turma B } & \mathrm{O}_{3} & \text { Tradicional } & \mathrm{O}_{4} & \mathrm{O}_{7} & \text { ABP } & \mathrm{O}_{8}\end{array}$

$$
\mathrm{O}_{1}=\mathrm{O}_{3} \text { e } \mathrm{O}_{2} \neq \mathrm{O}_{4} \quad \mathrm{O}_{5}=\mathrm{O}_{7} \text { e } \mathrm{O}_{6}=\mathrm{O}_{8}
$$

Fonte: Elaborado pelos autores a partir de Sampieri, Collado e Lucio (2013).

\section{Conclusão}

Apresentamos neste trabalho um estudo comparativo com delineamento quase experimental entre o método de ensino expositivo e uma metodologia de ensino ativa em nível de Educação Básica. Foram consideradas como variáveis dependentes a motivação para aprender, atitudes em relação à matemática e desempenho escolar.

A Aprendizagem Baseada em Projetos é um método de ensino que busca ensinar conteúdos curriculares utilizando situações reais e significativas aos alunos, com eles trabalhando de modo cooperativo, desenvolvendo um produto final como resultado de seus estudos e esforços. Assim, as habilidades e competências essenciais aos desafios do século 
XXI, tais como: criatividade, trabalho em equipe, resolução de problemas e pensamento crítico são desenvolvidos.

Neste sentido, a partir de estudos realizados fora do país que advogam incremento da motivação para aprender, engajamento dos alunos nas atividades dos projetos e melhor aprendizagem, nosso intuito foi investigar, dentro do contexto educacional brasileiro, os efeitos que este método de ensino, utilizado concomitante ao método tradicional, promoveu nos alunos do Ensino Médio sujeitos da pesquisa, de uma escola pública.

No aspecto motivação para aprender, as turmas, objetos de pesquisa, apresentaram em todos os momentos da aplicação do instrumento EMA-EM uma elevada motivação para aprender, na medida em que as médias se situaram bem próximas da amplitude máxima do instrumento. Nos testes estatísticos, não foram observadas diferenças significativas entre o método expositivo tradicional e a ABP.

No aspecto atitudes em relação a Matemática, os alunos das turmas apresentaram um comportamento heterogêneo com as médias das turmas, apresentando valores próximos a pontuação central da amplitude do instrumento EARM. Os resultados mostram que realmente existe uma relação de amor e ódio dos alunos com a Matemática, pois certa parcela de alunos situou-se no extremo superior da pontuação do instrumento e outra parcela se situou no extremo inferior.

No desempenho escolar, a ABP apresentou uma diferença significativa favorável em relação ao método tradicional, o que sugere uma melhor retenção de conteúdo curricular quando se utiliza a ABP.

Concluímos, apesar da amostra do estudo ser pequena, que a $\mathrm{ABP}$ é um método de ensino exequível na Educação Básica com resultados ligeiramente superiores ao método de ensino expositivo tradicional.

\section{Referências}

BARTSCHER, K.; GOULD, B.; NUTTER, S. Increasing student motivation through ProjectBased Learning. 1995. Dissertação (Mestrado em ??)- Saint Xavier University, Chicago, 1995.

BENDER, W. N. Aprendizagem baseada em projetos: educação diferenciada para o século XXI. Porto Alegre: Penso, 2014.

BRASIL. PDE: Plano de Desenvolvimentoda Educação. Prova Brasil. Ensino Fundamental. Matrizes de referência, tópicos e descritores. Brasília: Inep, 2008.

BRITO, M. R. F. Adpatação e validação de uma escala de atitudes em relação à matemática. Zetetiké, Campinas, v. 6, n. 9, p. 109-162, 1998. 
CAMPOS, D. M. D. S. Psicologia da aprendizagem. 39. ed. Petrópolis: Vozes, 2011.

CARDOSO, V.; SANTOS, J. C. D. As dificuldades no ensino aprendizagem da Matemática. Nativa Revista de ciências sociais do norte de mato grosso, Guarantã do Norte-MT, v. 1, n. 2, p. 1-15, 2014.

COSTA, J. D. M.; PINHEIRO, N. A. M.; PILATTI, L. A. O ensino de Matemática por meio de projetos de trabalho. III Simpósio Nacional de Ensino de Ciência e Tecnologia, 2012, Ponta GrossaPR. Anais do III SINECT, Ponta-Grossa-PR, 2012, p. 1-10.

D'AMBRÓSIO, U. Educação matemática: Da teoria à prática. 21. ed. Campinas: Papirus, 2010.

DANCEY, C. P.; REIDY, J. Estatística sem matemática para psicologia. 5. ed. Porto Alegre: Penso, 2013.

DIESEL, A.; BALDEZ, A.; MARTINS, S. Os princípios das metodologias ativas de ensino: uma abordagem teórica. Revista Thema, Pelotas-RS, v. 14, n. 1, p. 268-288, fev. 2017.

GARDNER, H. Inteligências múltiplas: a teoria na prática. Porto Alegre: Artmed, 1995.

GEORGE, D.; MALLERY, P. SPSS for Windows step by step: A simple guide and reference. 4. ed. Boston: Allyn \& Bacon, 2003.

KARAÇALLI, S.; KORUR, F. The effects of Project-Based Learning on students' academic achievement, attitude, and retention of knowledge: the subject of "Electricity in our lives". School science and mathematics, Purdue University-USA, v. 114, n. 5, p. 224-235, May 2014.

KRAJCIK, J. S.; BLUMENFELD, P. C. Project-Based Learning. In: SAWYER, R. K. (org.). The Cambridge handbook of the learning sciences. New York: Cambridge University Press, 2006. p. 317-334.

LARMER, J.; MERGENDOLLER, J.; BOSS, S. Setting the standard for project based learning: a proven approach to rigorous classroom instruction. Alexandria: ASCD, 2015.

LORENZATO, S. Para aprender matemática. 2. ed. Campinas: Autores Associados, 2008.

LOURENÇO, A. L.; PAIVA, M. O. A. D. A motivação escolar e o processo de aprendizagem. Ciências \& cognição, Rio de Janeiro-RJ, v. 15, n. 2, p. 132-141, 2010.

MALTEMPI, M. V. Construcionismo: pano de fundo para pesquisas em informática aplicada à Educação Matemática. In: BICUDO, M. A. V.; BORBA, M. D. C. (org.). Educação matemática: pesquisa em movimento. 3. ed. São Paulo: Cortez, 2009. p. 264-282.

MARCHIORE, L. D. W. O. A.; ALENCAR, E. M. L. S. D. Motivação para aprender em alunos do ensino médio. Educação temática digital, Campinas, v. 10, p. 105-123, 2009.

MARIN, M. J. S. et al. Aspectos das fortalezas e fragilidades no uso das metodologias ativas de aprendizagem. Revista Brasileira de Educação Médica, Brasília-DF, v. 34, n. 1, p. 13-20, 2010.

MARTINELLI, S. C. Um estudo sobre desempenho escolar e motivação de crianças. Educar em revista, Curitiba, v. 53, p. 201-216, set. 2014.

MARTINS, V. J. et al. A aprendizagem baseada em projetos (ABPr) na construção de conceitos químicos na potabilidade da água. Revista prática docente, Confresa, v. 1, no 1, p. 79-90, jul./dez. 2016. 
MORAN, J. M. Mudando a educação com metodologias ativas. Coleção mídias comtemporâneasconvergências midiáticas, educação e cidadania: aproximações jovens. v. 2. Ponta Grossa-PR, Editora UEPG, 2015.

NEVES, E. R. C.; BORUCHOVITCH, E. Escala de avaliação da motivação para aprender de alunos do ensino funamental (EMA). Psicologia: Reflexão e Crítica, Porto Alegre-RS, v. 20, n. 3, p. 406413, 2007.

NICOLETE, P. C. et al. Integração de tecnologias no ensino de Matemática na educação fundamental pública. Anais do Seminário de Pesquisa, Pós-Graduação e Inovação - SPPI, 2016. Disponivel em: https://publicacoes.rexlab.ufsc.br/index.php/sppi/article/view/42. Acesso em: 14 jul. 2017.

PAVANELO, E.; LIMA, R. Sala de aula invertida a análise de uma experiência na disciplina de cálculo I. Bolema, Rio Claro, v. 31, n. 58, p. 739-759, ago. 2017.

SAMPIERI, R. H.; COLLADO, C. F.; LUCIO, M. D. P. B. Metodologia de pesquisa. 5. ed. Porto Alegre: Penso, 2013.

VIANNA, S. C. G. et al. A implantação de métodos de aprendizagem ativos: uma experiência vivida no colégio ENIAC. Revista ENIAC pesquisa, Guarulhos-SP, v. 5, nº 2, p. 129-138, 2016.

YAP, B. W.; SIM, C. H. Comparisons of various types of normality tests. Journal of Statistical Computation and Simulation, Blacksburg-USA, v. 81, n. 12, p. 2141-2155, 2011. 